\title{
CREATION OF A MODEL FOR SOCIAL DEFENSE IN CASE OF DISASTERS FOR THE CITIZENS OF THE REPUBLIC OF BULGARIA
}

\author{
Georgi BAEV, Miroslav DIMITROV, Ivan DIMITROV \\ "Vasil Levski" National Military University, Veliko Tarnovo, Bulgaria \\ gbnvu@abv.bg, amirodimitrov@abv.bg, idimgb@gmail.com
}

\begin{abstract}
In Bulgaria there is a great need for a scheme for social defense and protection in case of natural or anthropogenic disasters. Our country has a relatively good social politics, covering a great deal of society's social illnesses. But our financial capabilities for natural and anthropogenic disaster prevention and handling present a great financial difficulty for our country's budget. In great deal of cases aid-money are being spend for covering material damage caused by natural disasters, but the aspect of affected citizens gets neglected and remains in the background. Our country comes as far as securing them with a one-off humanitarian or/and financial help for damaged property. In a great deal of cases though our country's help is inadequate in amount or gets postponed in time due to administrative procedures.
\end{abstract}

Keywords: national security, disaster, social defense

\section{Introduction}

In Bulgaria a high level of potential risk exist from the possibility of different disaster emergence due to natural processes or human activity that can prove to be fatal for the economic development of our country. [1]

Bulgarian scientists register a tendency in yearly temperature increase above the climatic norm in the country from the year of 1970 until today. Rainfall has also increased on an annual basis in most areas since 1990. It is not uncommon to see spring and summer temperatures during the winter months of the year.

Another evidence of climate warming in Bulgaria is the shortened vegetation period of some agricultural crops Under 90 days, according to 2010 data of the National Institute of Meteorology and Hydrology at the Bulgarian Academy of Sciences. [2] In the last 10 years, following the country's accession to the European Union, the national authorities have synchronized much of the local legislation with the EUwide directives, including the prevention DOI: $10.1515 / \mathrm{kbo}-2017-0003$

(C) 2017. This work is licensed under the Creative Commons Attribution-NonCommercial-NoDerivatives 3.0 License. and mitigation of disasters of a different nature.

\section{Method}

The research method includes research and analysis on the existing legislative framework in the sphere of natural disasters where a research issue is examined which concerns a high number of the country population. For the social protection in times of crises of natural origin is sought new approach drawn from existing academic models and system that were applied abroad but can be further utilized and applied.

\section{Legislative measures.}

Authorities have adopted the Disaster Protection Act, the Climate Change Reduction Act, the National Disaster Protection Plan, the National Disaster Protection Program, the Disaster Risk Reduction Strategy, the National Climate Action Plan. Amendments to other laws were also made, and then the Interdepartmental Commission for 
Reconstruction and Support to the Council of Ministers and the Center for Aerospace Disaster Surveillance were set up.

According to the strategy, in view of climate change, the state sector needs to be prepared with an adequate response policy. Due to the increasing intensity of disasters in the country, especially floods and forest fires, it has to be tackled with common efforts by different responsible institutions as the damage is of a social and economic nature. [3]

In order to achieve these goals, several key priorities for action are identified: providing adequate institutional support with a workable legal framework, enhancing early warning and climate forecasting capacities, culture and philosophy of crisis response training.[1]

\section{National problem}

Obviously, the social protection of society during and after disasters is not a separate strand. The country has a relatively good social policy covering a large part of the social disabilities of the population, but not when it comes to financial protection in disasters.

\subsection{Financial instruments}

The budget is most often used to cover material damage from natural disasters, but the injured people themselves remain in the background.

The state provides them with one-time allowances and / or with means of repairing the victims property.

In most cases, compensation is inadequate in amount or delayed due to administrative procedures.

The budget is used mostly for covering the material damage caused from natural disasters, but the actual injured people remain in the background.

The country is securing them with one-time financial help or with tools, that they can use to repair their property. However, the help from the country is inadequate very often, or it is coming slow, because of administrative procedures.
The savings of the citizens can not be accepted like an adequate capital for covering the damage, caused for repair. Therefore, the philosophy of the social help in the country needs to be rethought.

\subsection{Insurance market}

On the other side, to talk about development of the insurance markets in economies with low income is almost impossible.

This imposes more global effort to be made in order to cope with the problems of the environment and creating guarantee funds and investment policies. [4]

Among Bulgarian households there is no culture of insurance, and in many cases the insurance policies are not in their capability to buy, even though they are willing to buy them.

Overall, the confidence in insurance companies is relatively low and, often, the funds from the paid policies are not sufficient for rehabilitation activities. Therefore, less than $10 \%$ of households have insurance against floods and earthquakes.

There are also a variety of insurance products missing. In many cases, this activity is considered by citizens as unnecessary waste. [5]

\section{Social protection}

A good mechanism for solving environmental problems and affecting people's lives and property is the introduction of social protection schemes for disasters.

Through national and international funding, social protection measures are emerging as a real tool for counteracting crises and conflicts - both for people and for enhancing the environment.

In the rapidly developing modern world, the provision of social security conditions becomes an important function of public life, of the activities of all state bodies and institutions.

There are even forms of social protection of a private nature - pension insurance, 
medical services, social security. In Bulgaria a mixed social protection was created, using different organizational forms, although they are still incomplete.

Leading forms of social protection are: pension insurance, social benefits for particularly needy categories of the population, not only those who have experienced a difficult life situation or are in a socially dangerous situation but all people - from birth to the end of Life at different stages of their development. [6]

If a model or scheme for social protection is adopted, some of the measures certainly overlap with the current legislation, both in Bulgaria and in many other countries. However, the idea is that integrating them into a common system could lead to more flexible legislation and to attract more funding under international climate change mitigation programs.

The proposal is the first section of the Social Protection Scheme for Disasters to be "Social Security Networks".

This concerns the legislative instruments by which victims receive non-insurance benefits to obtain food coupons and other essential necessities.

The second section concerns the government's assumption of social and health insurance costs for those affected by disasters for the period of liquidation.

The third - includes measures on the labour market - unemployment benefits, as well as priority provision of employment to people affected by disasters, when it is not a matter of traumatism.

However, wealth is not the only determining factor. Disaster preparedness policies and higher education in this area are needed to help both the poor and the rich. Unprecedented crisis situations from environmental disasters require a robust risk mitigation policy. Scientific and academic knowledge is crucial for decision-making in crises and conflicts of such kind [7].
Thus however is completely insufficient a new comprehensive policy is needed that includes the development of high-tech, remote Earth exploration through satellites, support for new legislative policies of a social nature, knowledge exchange and information on environmental risks, early warning systems for disasters, unlocking the potential for interstate cooperatives for monitoring and response new and more flexible financial and insurance instruments and much more.

\section{Conclusions}

All facts point that Bulgaria is also affected by both natural disasters and the climate changes that are often manifested in the country. The existing research allows us to draw the conclusion that a more decisive political will is needed for coping with the disasters and the social consequences that follow them.

The occurrence of crisis events of ecological origin would be a threat to a significant percentage of the population and the consequences would be most devastating for the most vulnerable groups in society.

The lack of insurance culture, the low social status and educational level and limited information on the topic for a large part of the population are different negative factors that need to be considered in such analysis. All of the above combined with a limited state budget leads to a poor social policy that would be related not only to a social status but also to crisis management and reaction.

Despite the deepening negative tendencies, there is a possibility the topic to get higher on the agenda of the society and respectively in the agenda of the political class. The academic community would be very helpful with its scientific research that is already in place and their final results to be well structured and applicable schemes for social protection.

\section{References}

[1] The Disaster Risk Reduction Strategy of Bulgaria 2014-2020, Sofia, 2014 pp. 2-27. 
[2] Alexandrov V., Simeonov P., Kazandzhiev V., Korchev G., Yotova A, "Climate Changes", The National Institute of Meteorology and Hydrology at the Bulgarian Academy of Sciences, Sofia 2010, pp. 3-31

[3] The National Disaster Protection Plan, Council of Ministers, Sofia, 2010, pp.2-40

[4] S. Hallegatte, Bangalore M., Bonzanigo L., Fay M., Kane T., Narloch U., Rozenberg J., Treguer D., Vogt-Schilb A., Washington, Shock Waves, Managing the Impacts of Climate Change on Poverty, Washington, 2015, pp.1-18

[5] www5.moew.government.bg

[6] Radev N., Social protection technologies, Sofia, GorexPress, 2007, pp 81-125

[7] De Groeve T., Al Khudhairy D., Annunziato A., Clark I., Bower A, Surveying the landscape of science/policy interfaces for disaster management policy making and operations, Publications Office of the European Union, 2015, pp.10-50 